\title{
GRUPO EDITORIAL COMPANHIA DAS LETRAS: TRANSIÇÃO DA ARQUITETURA DE MARCA ENDOSSADA PARA A DE MARCA PLURALISTA
}

Regina Cunha Wilke

Centro Universitário Senac

regina.cwilke@sp.senac.br

Resumo: A Editora Companhia das Letras, além da linha editorial definida pela qualidade de seus textos, é reconhecida pelo tratamento visual e gráfico dos seus livros. Sua arquitetura de marcas inicial é constituída por um sistema que segue a mesma lógica de construção de sinais, que endossados pela marca mãe, constitui parte de seu diferencial e sucesso no mercado editorial. Em 2012, a empresa começa a se reestruturar como um grupo editorial em que cada selo compõe uma unidade independente. Em 2014 se transforma em Grupo Editorial Companhia das Letras. O objetivo deste artigo é refletir sobre a construção da sua arquitetura de marcas, a sua relação com a estratégia de negócios e com a percepção do consumidor. Este tipo de estudo faz parte do projeto de pesquisa "Memória gráfica brasileira: design, processos e linguagens visuais" que tem o propósito de contribuir para o desenvolvimento de estudos sobre a história recente e a teoria do design. Considera a investigação de exemplos relevantes de manifestações visuais dos últimos 50 anos na cidade de São Paulo. Busca investigar as linguagens gráficas dominantes, as mudanças geradas pela tecnologia e a história empresarial.

Palavras-chave: marcas, grupo editorial, Companhia das Letras.

Abstract: Companhia das Letras, besides to the editorial line defined by the quality of his texts, it is recognized by the style of graphic of his books. The construction of its architecture brand, initially constituted by a system that follows the same signs of the construction logic, guaranteed by the parent brand, it is part of your success. In 2012 the company starts to restructure as a publishing group in which each seal comprises an independent unit. In 2014 becomes Grupo Editorial Companhia das Letras. The aim of this paper is to discuss the construction of its brand architecture, its relationship with the business strategy and consumer perception. This type of research is part of the Project: "Brazilian Graphic Memory: design, processes and visual languages", that aims to contribute to the development of studies on recent history and theory of design. Considers research relevant examples of visual manifestations of the last 50 years in the city of São Paulo. The dominant investigates graphic languages, the changes generated by technology and business history.

Keywords: brands, publishing group, Companhia das Letras 


\section{INTRODUÇÃO}

O artigo, a partir de um levantamento do mercado editorial de livros e das principais editoras paulistanas, seleciona a Editora Companhia das Letras e apresenta um estudo sobre sua arquitetura de marcas. Essa editora foi escolhida pela qualidade e reconhecimento de sua produção e por ter se transformado em Grupo Editorial Companhia das Letras, ao adquirir o controle da editora Objetiva, que pertencia a Penguin Random House. Nessa transição de negócio, ela incorpora novas marcas individuais para os seus diferentes mercados-alvo, alterando a arquitetura de marcas original. Este tipo de estudo, análise das marcas, pode nos dizer sobre repertórios, tendências, gostos e sobre história empresarial.

Ele faz parte do projeto de pesquisa "Memória gráfica brasileira: design, processos e linguagens visuais", que tem o propósito de contribuir para o desenvolvimento de estudos sobre a história recente e a teoria do design. Considera a investigação de exemplos relevantes de manifestações visuais dos últimos 50 anos na cidade de São Paulo.

Inicialmente, entendemos a evolução do mercado editorial e realizamos um levantamento das principais editoras, nessa etapa foram consultados os autores Helewell (2012), SNEL (2014). Sobre a Companhia das Letras, consultamos Schwarcz (2012, 2015), e para entender sobre a fusão, consultamos o blog da editora e Carrenho (2014). A identificação das marcas foi realizada com consulta ao site oficial da Editora. Após a descrição e análise das marcas, seguimos as denominações e conceitos ditados por Wheller (2012) e Aaker (2001) para ler a organização do sistema de marcas.

\section{MERCADO DE LIVRO NO BRASIL}

Em quase 60 anos, de 1917 a 1980, o mercado de livros no Brasil cresceu quase cem vezes. O Brasil moderno possui dois centros editoriais principais, São Paulo e Rio de Janeiro, que juntos são responsáveis pela esmagadora maioria de livros produzidos no Brasil. (HALLEWELL, 2012, p. 269-270).

Segundo Hallewell (2012, p. 277), o mercado editorial brasileiro sofreu grande alteração na década de 70 , a venda a varejo prosperou e o número total de editoras comerciais aumentou consideravelmente no país. A partir dos anos 80 , o crescimento continuou ascendente, novas editoras surgiram e diversificaram o cenário editorial nacional, muitas das antigas foram substituídas ou incorporadas a outras. Na década de 90, Hallewel (2012, p.816) aponta cinco principais editoras na área de livros gerais, a saber: Record, Companhia das Letras, Rocco, Objetiva e Nova Fronteira.

Em 2010, a revista britânica "Wallpaper" em um número totalmente dedicado ao Brasil trouxe uma chamada de capa que anunciava um boom de livros no Brasil, fato divulgado pela Associação Nacional de Livrarias (ANL). Neste mesmo ano, o Valor Econômico promoveu uma enquete com um grupo de críticos e professores para identificar quais as melhores editoras do Brasil, e quais as que mais se destacam culturalmente. Os critérios para medir a qualidade das editoras se pautavam pelo destaque nas áreas artístico-literária e das ciências humanas, na capacidade de interferir na vida cultural e de formar leitores. A Companhia das Letras ficou em primeiro lugar, com $81 \%$ dos votos. (FERRARI, 2010) 
Em 2014, essa editora tornou-se um selo da empresa Penguin Random House. Se une à editora Objetiva sob o mesmo guarda-chuva, compondo o Grupo Companhia das Letras. (CARRENHO, 2014)

\section{COMPANHIA DAS LETRAS}

Luiz Schwarcz criou a Editora Companhia das Letras em 1986, no mesmo ano que saiu da Brasiliense, onde foi o braço direito de Caio Graco Prado (1931-1992). Teve um papel decisivo na transformação desta editora, que estava quase estagnada na década de 60 (CARUCCI, 2012). Iniciou como estagiário em 1978, alcançou a função de gerente editorial, que é, segundo Hallewell (2012, p. 237), quem cuida da escolha dos manuscritos, de sua revisão e transformação em textos prontos para serem lançados. Ele foi a alma da Brasiliense durante muito tempo.

Schwarcz (2012) explica: "Funcionei como a pessoa que pegava as ideias geniais do Caio e dava um acabamento necessário para que aquela ideia ficasse redonda". A imprensa o descobriu e sua fama e sucesso passaram a se sobressair ao próprio dono da editora. "Decidi que queria sair de lá, porque achava que, de certa maneira, estava começando a disputar a Brasiliense com o Caio. A gente tinha visões diferentes". (SCHWARCZ, 2006)

Luiz deixou a Brasiliense em 1986 para fundar sua própria editora, a Companhia das Letras. A Brasiliense perdeu vários autores que optaram por mudar seus livros para a editora de Schwarcz, o que ocasionou o fechamento de diversas lojas da Brasiliense, que permaneceria nas mãos de Caio Graco Prado até 1992, ano de sua morte.

É importante ressaltar que a editora Civilização Brasileira foi, em grande parte, a responsável por criar uma linguagem gráfica editorial de alto nível no Brasil. Eugênio Hirsch, diretor de arte e autor de capas dessa editora, em geral tipográficas, é hoje referência para qualquer história do design gráfico do nosso país. (SCHWARCZ, 2011). Hirsch assinava todas as capas da editora Civilização Brasileira. A Companhia das Letras levou adiante o processo de renovação iniciado pela Brasiliense (Melo, 2011, p.566).

Em 1991 ocorre o reconhecimento da importância do capista. Foi nesse ano que surgiu o prêmio Jabuti para melhor capa, dado a Ettore Bottini da Companhia das Letras. O Museu da Imagem e do Som realizou, então, uma exposição A Arte da Capa, dedicada à obra de Ettore Bottini, de Eugênio Hirsch, da Civilização Brasileira, De Moema Cavalcanti das Duas Cidades e de Jõao Batista Aguilar, da Companhia das Letras. (HALLEWEL, 2012, p.819).

O trabalho dos capistas da Companhia das Letras impulsionou o nível de qualidade do design brasileiro. Assim como o produto livro, que com o uso de papel amarelo nas páginas reflete menos a luz e o respeito às entrelinhas, traz uma leitura agradável. Esses detalhes são creditados a Schwarcz (2011).

A empresa Companhia das Letras, cuja produção era dirigida para o consumidor diferenciado, desde sua criação em 1986, parece ter sofrido menos impacto das sucessivas crises da indústria (HALLEWEL, 2012, p.809). Hoje, a Editora se transformou no Grupo Companhia das Letras e mantém a ideia inicial presente na sua origem, a de valorizar a qualidade literária, marco fundamental na personalidade do grupo. Esse respeito à literatura ainda é fundamental na escolha dos detalhes da produção do livro. 
A Companhia das Letras inicia um movimento forte de consolidação do mercado brasileiro em 2015, quando torna-se um selo da Penguin Random House . A união da Companhia das Letras com a editora Objetiva é consequência direta da aquisição de todos os selos literários da espanhola Santillana pela Penguin Random House (PRH). A PRH é dona de $45 \%$ da Companhia das Letras e a Santillana tinha $76 \%$ da Objetiva. Assim, as empresas se uniram sob o mesmo guarda-chuva. (CARRENHO, 2014). O Grupo Companhia das Letras é composto pelos selos da Companhia das Letras e pelos selos da Objetiva, num total de 19 selos.

\section{GRUPO COMPANHIA DAS LETRAS}

O nome "Companhia das Letras" foi criado a partir de um encontro de Luiz Schwarcz com Zé Paulo Paes, memorável editor da Cultrix, tradutor e poeta. Paes sugeriu o nome "Letras e Companhia". Posteriormente, em uma conversa entre Schwarcz e o artista gráfico João Baptista da Costa Aguiar (1948), o nome Companhia das Letras foi estabelecido, inspirado no da organização comercial dos tempos coloniais, Companhia das Índias". Schwarcz (2011) explica "Como se fosse possível viajar através da literatura. Pensando nesse nome, nós imaginamos o logotipo como uma caravela". Mas isso negava a ideia central, pois o objetivo principal era variar e diversificar as viagens, seria mais radical um logotipo múltiplo para sempre lembrar ao leitor que ele estará viajando nas suas leituras. Assim, imagens com os símbolos do viajante definiriam o perfil da Companhia das Letras.

João Baptista encontrou clichês tipográficos em um catálogo de gráfica francesa do final do século XIX que pertencia ao artista plástico Carlos Matuck. Em meio a esse arquivo, havia uma página com imagens de meios de transportes (trem, bicicleta, avião, veleiro) que passaram a ser utilizados na marca, cumprindo o objetivo de adequar a marca ao conceito, criando assim, uma diversidade na unidade. Dessa forma, cada livro seria composto pela marca com o desenho do meio de transporte que mais parecesse compatível. Por exemplo, na primeira edição do livro "Rumo à estação Finlândia", o desenho da marca seria o trem; na edição de "Tudo que é sólido se desmancha no ar", o desenho da marca passa a ser um avião. Schwarcz (2011)

Segundo Melo (2011, p.566), "O salto conceitual é adotar não um sinal, mas uma família de sinais; trata-se de uma abordagem pioneira em projetos de larga escala e difusão, baseado no aumento da ênfase dos componentes variáveis dos sistemas de identidade corporativa".

A arquitetura da marca da Companhia das Letras foi composta pelo desdobramento dos elementos gráficos usados pela marca mãe, a saber, símbolo, composto pela representação de um meio de transporte, tipografia e fios,

\footnotetext{
1 Companhia da Índia Oriental é o nome dado a diversas companhias europeias que iniciaram o comércio com a Índia e o Extremo Oriente, durante o séc. XVII. Constituíam empresas privadas que recebiam privilégios dos governos da Inglaterra, Países Baixos, Dinamarca e França. Investidores, chamados já à época de capitalistas, trocam e negociam as partes ou ações que detinham nas companhias mercantis, vistos como pilar do capitalismo moderno. "A Companhia das Índias Orientais foi um dos principais fatores da grande virada de desenvolvimento global que marcou o nascimento da era moderna" (Hoje na História: 1602 - É inaugurada a Companhia das Índias (Max Altman | São Paulo 20/03/2012 < operamundi.uol.com.br/conteúdo/notícias/20626/>
} 
posicionados entre o símbolo e o logotipo, que, grafados de forma flexível buscam expressar o conteúdo de cada selo, dando-lhes uma identidade gráfica particular construindo um sistema. O primeiro selo da editora foi criado em 1992, chamado Companhia das Letrinhas, destinado ao público infantil, caracterizado pela tipografia, símbolo e os fios que denotam desenhos feitos à mão, numa associação à expressão gráfica de criança. Dois anos depois, surgiu a Cia. Das Letras, com obras de ficção e não ficção para pré-adolescentes e adolescentes. O nome da marca sofre uma redução, despojamento esse reforçado pela fonte sem serifa, que somado aos fios pontilhados e à imagem em alto contraste constroem uma imagem atualizada para o público jovem (fig.1).
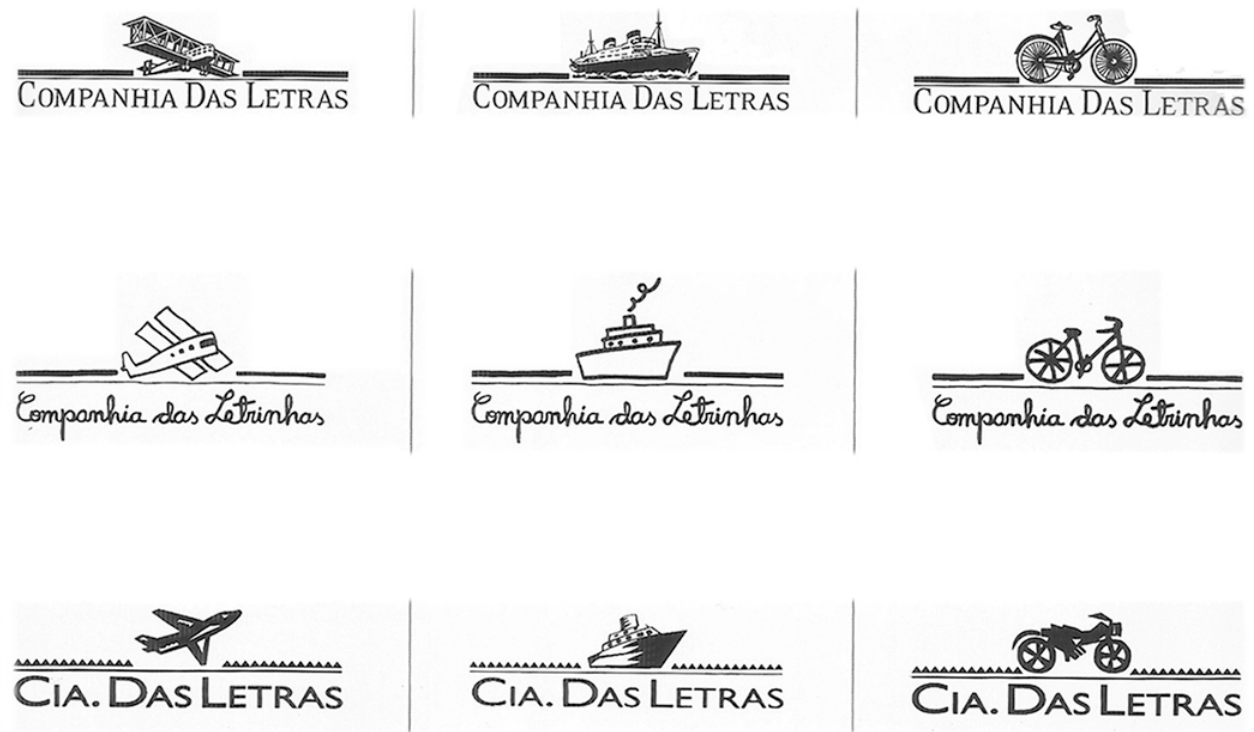

Figura 1 - Marca da Companhia das Letras, criada em 1986, e dos selos Companhia das Letrinhas, criada em 1992 e Cia. das Letras, criadas em 1994.

FONTE: LEON, 2006, p. 101

Posteriormente, a marca da Companhia das Letras, e sua diversidade de símbolos, foi redesenhada recuperando as arestas dos desenhos e atualizando a fonte tipográfica (fig. 2).

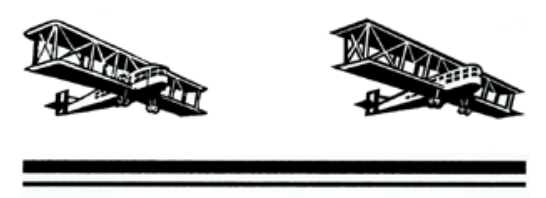

COMPANHIA DAS LETRAS

COMPANHia DAS LETRAS

Figura 2 - Marcas do selo Companhia das Letras, de 1986 e redesenhadas.

Fonte: LEON, 2006, p. 98 
Em 2005, a Companhia de Bolso (fig. 3) foi criada com a intenção de publicar livros em edições econômicas, para tornar o livro ainda mais acessível e ampliar sua importância no cotidiano brasileiro. A marca composta por lettering, desenhos e fios leves, sugere a associação de esboços, algo rápido e corriqueiro do dia a dia do leitor. Identifica a versão econômica dos sucessos da editora. Em 2009 foi lançado Quadrinhos na Cia (fig. 4), selo que insere a figura do herói em sua marca, seus fios sugerem ação, movimento e somados ao desenho da tipografia em caixa alta fazem uma associação direta ao gênero.
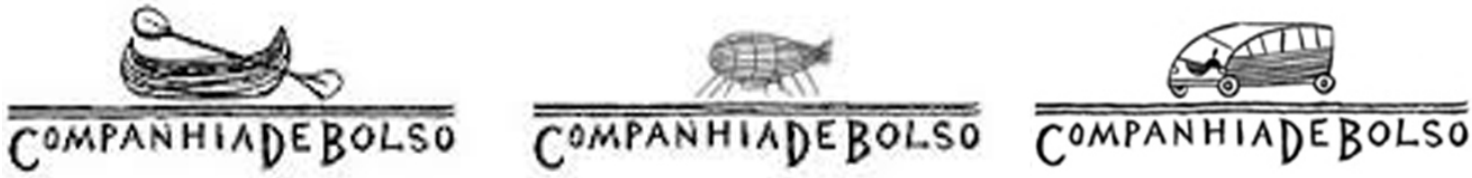

Fig.3 - Marcas do selo Companhia de Bolso

Fonte: Elaborado pelo autor, com base na pesquisa realizada.
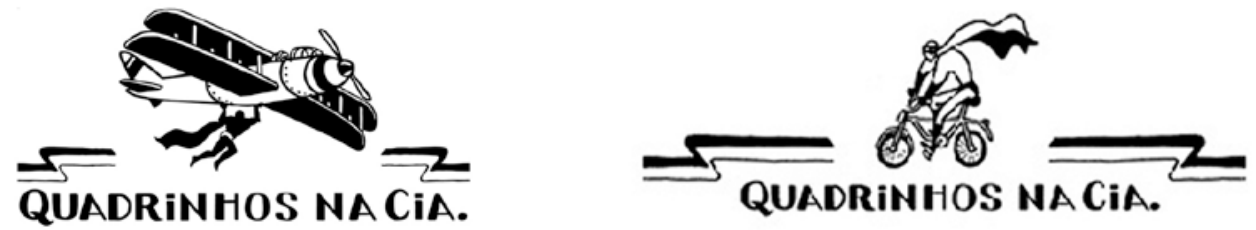

Fig.4 - Marcas do selo Quadrinhos na Cia

Fonte: Elaborado pelo autor, com base na pesquisa realizada.

Em setembro desse mesmo ano, a Companhia das Letras se associou à Penguin Books. A partir de 2010, o selo Penguin Companhia (fig. 5) edita, em português, as obras do catálogo da Penguin Classics, com o formato internacionalmente reconhecido da coleção, além de novos projetos idealizados especialmente para a coleção. (COMPANHIA DAS LETRAS, 2015).

\section{PE N G U I N}

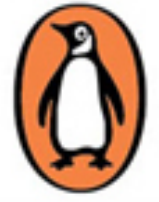

\section{COMPANHIA DAS LETRAS}

Fig.5 - Marca da Penguin Companhia das Letras

Fonte: Elaborado pelo autor, com base na pesquisa realizada.

Dessa primeira fase, da arquitetura de marcas endossadas, fazem parte selos comemorativos (Fig.6), que confirmam a flexibilidade e amplitude de representações possibilitadas pelos recursos gráficos da marca da editora.

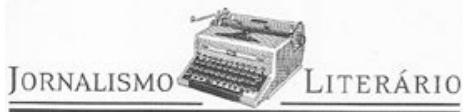

COMPANHIA DAS LETRAS

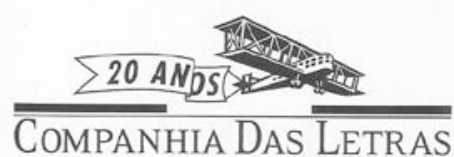

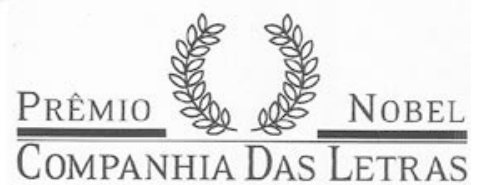

Fig.6 - Selos comemorativos

FONTE: LEON, 2006, p. 100 
No mesmo ano 2009, a Companhia das Letras lança a Editora Claro Enigma (fig.7), para publicações de material paradidático direcionados a profissionais ligados a educação. O diferencial está no rompimento com a estética anterior, onde o logotipo não carrega mais referência ao nome Companhia das Letras e ganha independência. $O$ contraste de peso separa as palavras que constituem o nome da marca, numa tipografia sem serifa, simples. A semântica das palavras, que compõem o nome desta editora pode significar o "que ilumina" e "o dito ou fato de difícil interpretação" (definições do dicionário Michaellis). Ou pode fazer referência à Claro Enigma, uma obra de Carlos Drummond de Andrade considerada um rompimento no trabalho do autor por ser diferente do que ele fazia até então. O primeiro significado adjetiva essa linha de livros paradidáticos, a segunda pode ser associada ao novo rumo das marcas da Editora.

\section{claroenigma}

Fig.7 - Editora Claro Enigma em 2009.

Fonte: Schwarcz (2012).

Em 2011, lança o selo Má Companhia, dedicado a obras polêmicas, autores considerados malditos ou transgressores pelo mercado, o selo publicou 6 obras entre 2011 e 2013, consideradas uma coleção (fig.8). Outros selos de coleções mantém a marca da editoria a que pertencem, mas podem sofrer pequenas alterações, como serem grafados sem os meios de transporte, por exemplo.

\section{MA EOMPANHIA}

Fig.08 - Selo Má Companhia

Fonte: Elaborado pelo autor, com base na pesquisa realizada

A partir de 2013, fica explícita a intenção e a motivação de não usar mais o nome da editora aglutinado aos novos selos. Schwarcz (2015) explica que a empresa começa a se reestruturar como um grupo editorial, em que cada selo compõe uma unidade independente, com atuação paralela ao catálogo da Companhia das Letras, como se fossem novas editoras.

Dentro desta proposta, quatro novos selos são lançados:

Editora Paralela (2012), voltada para a publicação de livros de entretenimento destinados ao grande público. A disposição das sílabas que compõem o nome, com alinhamento forçado, alinhado em cima e embaixo, em paralelo, sugere o propósito da marca, de lançar simultaneamente os títulos e sua versão em e.book (fig.9).

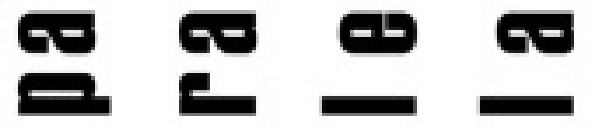

Fig.9 - Marca da Editora Paralela.

Fonte: Schwarcz (2012) 
Editora Seguinte (2012), o novo selo jovem da Companhia das Letras, foi aos poucos substituir a $\mathrm{CIA}$ das Letras. O nome composto de tipos não alinhados na base e a presença de detalhes de novas letras, entrando e saindo do espaço central, sugerem uma transformação que acontece no tempo. Ao se clicar na marca no ambiente digital, sinais tipográficos substituem letras, estabelecendo uma metáfora de possíveis narrativas, de diversão, com as quais o jovem vai interagir (Fig.10). Este selo, aos poucos, vai substituir o $\mathrm{ClA}$ das Letras, que deixará de existir.

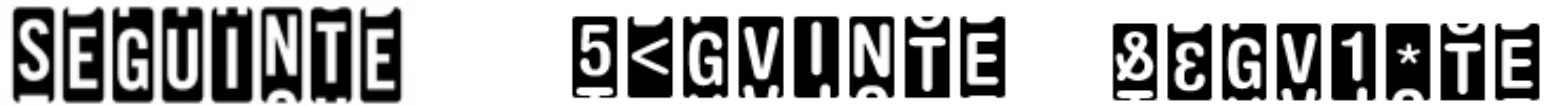

Fig.10 - Marca da Seguinte, um selo jovem da Companhia.

Fonte: Schwarcz (2012)

Boa Companhia (2012), série que reunirá grandes nomes da literatura nacional e estrangeira. A construção da marca recorre aos mesmos elementos gráficos e fonte tipográfica da marca da Editora Companhia das Letras, compondo uma imagem lúdica, a palavra "boa" acentua o significado da palavra companhia, reforçada pela gangorra, uma alavanca que funciona com a participação de duas pessoas de pesos comparáveis, de um lado os autores e do outro os leitores desse selo (Fig.11).

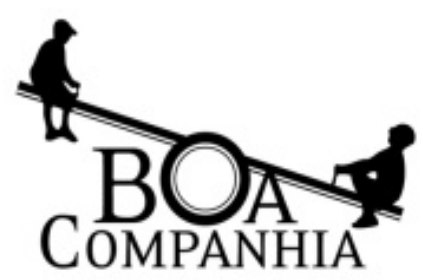

Fig.11 - Marca da Editora Boa Companhia (2012)

Fonte: Schwarcz (2012)

A quarta dessas novas marcas é o Portfolio Penguin (fig.12), que atua na área de negócios, política e economia. O símbolo busca proximidade com a Marca Penguin, por meio do uso da cor laranja, do formato oval e da imagem em preto. A imagem do homem arremessando uma lança aponta significativamente para cima, associando a ideia de crescimento.

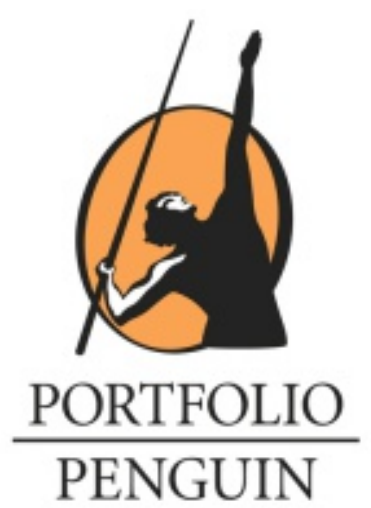

Fig.12 - Portfolio-Penguin

Fonte: Grupo Companhia das Letras (2015) 
O selo Breve Companhia (fig.13) é composto por ebooks de obras inéditas. 0 nome, por vezes, é identificado pelo gênero, poemas, ensaio, reportagem, entre outros, grafado em tipografia em caixa alta sem serifa, é endossado pela marca da Companhia das Letras nas aplicações em capa dos livros. O selo Breve Companhia foi descontinuado do fim de 2014 (VARELLA, 2015).

\section{BREVE COMPANHIA}

Fig.13 - Marca da Editora Breve Companhia (2013)

Fonte: Elaborado pelo autor, com base na pesquisa realizada

Ao incorporar marcas individuais para os seus diferentes mercados-alvo, altera a arquitetura de marca original e antecipa uma transição de negócio, a constituição de um grupo editorial.

Em 2014, o Grupo Companhia das Letras nasce como um dos maiores do mercado editorial brasileiro, com 19 selos. Os selos que integram o novo grupo são: Alfaguara, Alfaguara Infantil, Boa Companhia, Breve Companhia, Claro Enigma, Companhia das Letras, Companhia das Letrinhas, Companhia de Bolso, Foglio, Fontanar, Objetiva, Panelinha, Paralela, Penguin-Companhia, Ponto de Leitura, Portfolio-Penguin, Quadrinhos na Companhia, Seguinte e Suma de Letras (fig.14).

Os selos e catálogos seguem independentes, fato normal no caso de fusões e aquisições de sucesso (CARRENHO, 2014). Os autores continuarão a ser publicados em seus respectivos selos e a sede do grupo continuará em São Paulo, enquanto a editora Objetiva manterá operações no Rio de Janeiro.

Da arquitetura inicial de marcas endossadas, a Companhia das Letras num processo de concepção de novos selos que representem novas editoras, passa a uma arquitetura pluralista. Esta estratégia amplia a visibilidade das novas editoras e condiz com a nova imagem de grupo editorial.

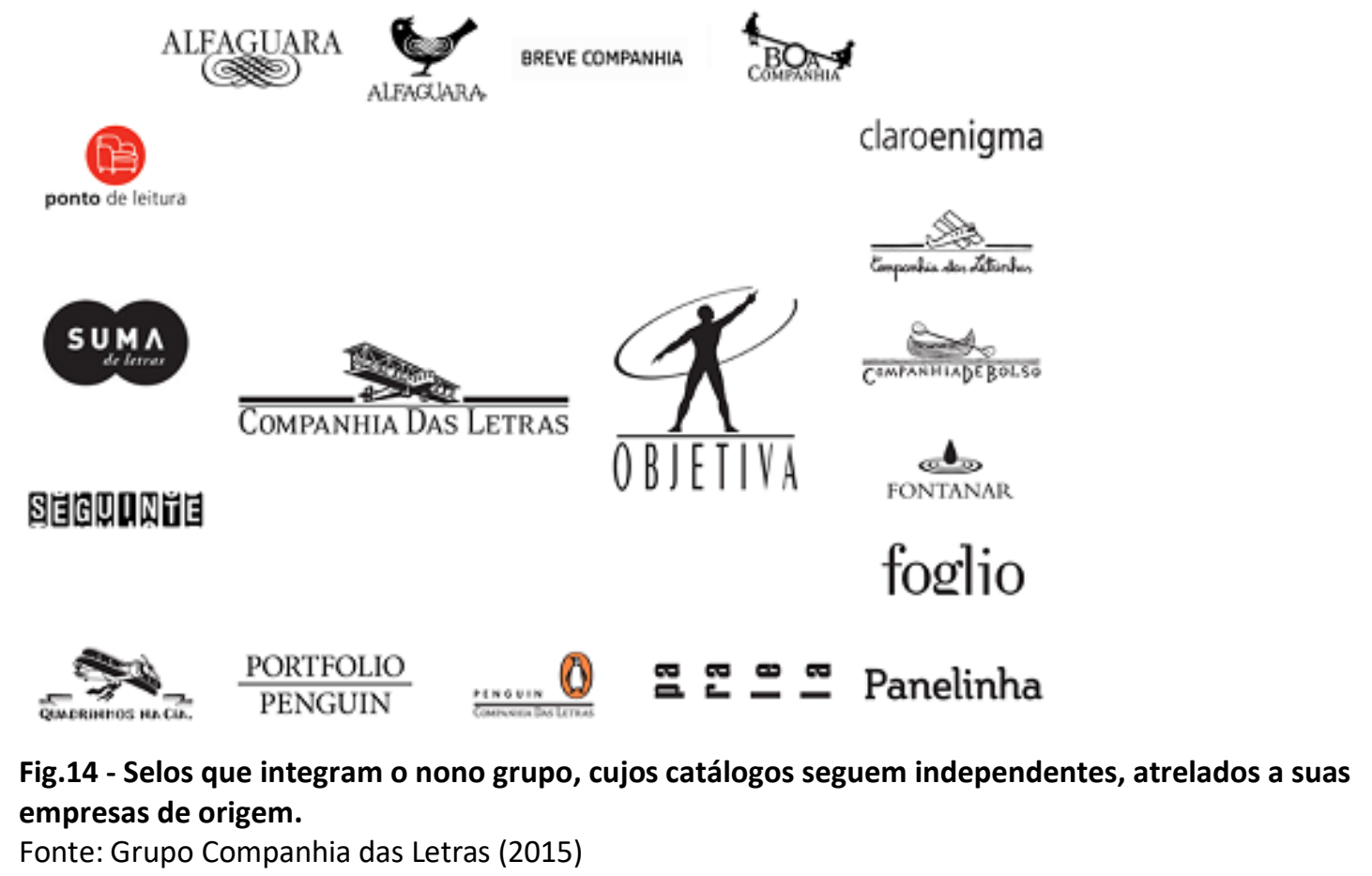


A união entre Companhia e Objetiva é mais um passo em um longo processo de consolidação do mercado, que reflete uma tendência mundial.

\section{CONCLUSÃO}

Verificamos que a identidade da marca corporativa da Companhia das Letras guarda uma relação íntima com a imagem e ideais da Companhia das Letras. Seu nome tanto tem o sentido de organização empresarial, como se reporta à Companhia das Índias Orientais que propiciou um desenvolvimento global, marcando o nascimento da era moderna. Essa ideia foi reforçada pelo símbolo dos meios de transporte e se fez presente nos selos da empresa. Quando a Penguin Classics passa a ser parceira da Companhia das Letras, suas marcas de juntam, o logotipo e o famoso símbolo da Penguin ocupam o lugar do meio de transporte, qualificando-se respectivamente.

A partir de 2013, a estratégia empresarial é a de criar selos independentes que sejam vistos como novas editoras. Os nomes dos novos selos representam a essência dos mesmos e suas conotações são voltadas para o mercado a ser atendido. Alguns ainda trazem parte do repertório gráfico da marca da Companhia das Letras, mas com a linguagem renovada ou são apoiados por esta na aplicação da capa dos livros. Outros expressam mais enfaticamente sua independência. A CIA das Letras foi substituída aos poucos pela marca Seguinte, que traz um conceito gráfico atualizado, e eliminada na formação do grupo.

As marcas endossadas se mostraram um bom caminho para reter o poder da marca mãe, sua presença e visibilidade, e isso permitiu aos selos desenvolverem associações e personalidade próprias. Com os interesses mercadológicos renovados, selos com logotipos autônomos passam a se organizar como um novo sistema de marcas. Este tipo de arquitetura da marca pluralista (WHELLER, 2012) estabelece a hierarquia das várias marcas da Editora Companhia das Letras, confirmando suas metas e apoiando o crescimento futuro da empresa.

A união entre Companhia e Objetiva, cada uma com um catálogo particular de selos, concentram uma diversidade de editorias direcionadas a uma ampla gama de leitores, e retratam uma tendência no mercado mundial de livros, a da fusão de editoras em Grupos Editoriais.

Essa pesquisa aponta para uma continuidade, para complementar informações que surjam no transcorrer desse processo em andamento da construção do grupo editorial. Outros estudos particularizados devem ser realizados sobre demais editoras.

\section{REFERÊNCIAS}

AAKER, David. Criando e administrando marcas de sucesso. São Paulo, Futura, 2001. BRASIL, Ubiratan, PENNAFORT, Roberta. Penguin Randon House adquire Editora Objetiva. 19/03/2014. Disponível na internet por http em: <http://cultura.estadao.com.br/noticias/geral,penguin-random-house-adquireeditora-objetiva,1142653> Acesso em 16 out. 2015

CARRENHO, Carlo. Mercado em processo de consolidação [Artigo publicado originalmente na edição de 21/3/2014 de O Estado de S.Paulo] Disponível na internet 
por http em: < http://www.culturaemercado.com.br/site/pontos-de-vista/mercadoem-processo-de-consolidacao/> Acesso em: 16 out. 2015

CARUCCI, Pedro; DAHER, Gabriel; e MIRANDA, Victor. O Último Voo - Os anos 80 da Editora Brasiliense. Trabalho de Conclusão do Curso de Jornalismo na Faculdade Cásper Líbero. Publicado em 18 nov. 2012. 32'36". Disponível na internet por http em:

<https://www.youtube.com/watch?v=9S8yeuhNkE4>. Acesso em: 30 out. 2015

GRUPO COMPANHIA DAS LETRAS. Comunicado Grupo Companhia das Letras. São Paulo, 2015. Disponível na internet por http em:

<http://www.blogdacompanhia.com.br/2015/04/comunicado-grupo-companhia-dasletras/ Acesso em: 11 set. 2015

HALLEWELL, Laurence. O livro no Brasil (sua história). São Paulo: EDUSP, 2012.

LEON, Ethel. João Batista da Costa Aguiar. São Paulo: Senac, 2006.

MELO, Chico Homem, RAMOS, Elaine. A linha do tempo do design no Brasil. Cosac Naify, 2011.

O ESTADO DE S. PAULO. Após fusão, editoras formam o novo Grupo Companhia das Letras. O ESTADO DE S. PAULO, 2015. Disponível na internet por http em:< http://cultura.estadao.com.br/noticias/literatura,apos-fusao-editoras-formam-o-novogrupo-companhia-das-letras,1662122\#> Acesso em: 16 out. 2015

SCHWARCZ, Luiz. As entrelinhas merecem respeito. 2011. Disponível na internet por http em: <http://www.blogdacompanhia.com.br/2011/06/as-entrelinhas-merecemrespeito/ 2 junho 2011> Acesso em: 18 set. 2015

SCHWARCZ, Luiz. Companhia das Letras lança quatro novos selos. 2012. Disponível na internet por http em:<http://www.blogdacompanhia.com.br/2012/03/companhia-dasletras-lanca-quatro-novos-selos/ > Acesso em: 18 set. 2015

SNEL - Sindicato Nacional de Editores de Livro. Disponível na internet por http em:< http://app.snel.org.br/ui/associado/listaAssociado.aspx> acessado em 28 ago. 2015.

VARELLA, João. O calvário dos e-books. 07/04/2015. Disponível na internet por http em: <http://www.istoedinheiro.com.br/noticias/mercado-digital/20150407/calvario-dos-ebooks/247797> Acesso em: 29 jan. 2016

FERRARI, Márcio. Letras Maiúsculas. Valor Econômico, 28/07/2010. Disponível na internet por http em:<http://www.apaginadistribuidora.com.br/noticias/detalhes/47> Acesso em: 28 ago. 2015.

WHELLER, Alina. Design de identidade de marca. São Paulo: Bookman, 2012. 